\title{
Progress Towards Ignition on the National Ignition Facility
}

J. D. Lindl, E. I. Moses, L. J. Atherton, R. W. Patterson, B. M. Van Wonterghem, B. J. MacGowan, M. J. Edwards, S. Glenzer, S. W. Haan, A. V. Hamza, C. A. Haynam, J. D. Kilkenny, O. L. Landen, L. J. Suter, P. J. Wegner

October 14, 2010

Progress Towards Ignition on the National Ignition Facility Daejeon, South Korea October 11, 2010 through October 16, 2010 
This document was prepared as an account of work sponsored by an agency of the United States government. Neither the United States government nor Lawrence Livermore National Security, LLC, nor any of their employees makes any warranty, expressed or implied, or assumes any legal liability or responsibility for the accuracy, completeness, or usefulness of any information, apparatus, product, or process disclosed, or represents that its use would not infringe privately owned rights. Reference herein to any specific commercial product, process, or service by trade name, trademark, manufacturer, or otherwise does not necessarily constitute or imply its endorsement, recommendation, or favoring by the United States government or Lawrence Livermore National Security, LLC. The views and opinions of authors expressed herein do not necessarily state or reflect those of the United States government or Lawrence Livermore National Security, LLC, and shall not be used for advertising or product endorsement purposes. 


\title{
Progress Towards Ignition on the National Ignition Facility
}

\author{
J.D. Lindl, E. I. Moses, L.J. Atherton, R. W. Patterson, B.M. VanWonterghem, B.J. \\ MacGowan, M.J. Edwards, S. Glenzer, S.W. Haan, A.V. Hamza, C.A. Haynam, J.D. \\ Kilkenny, O.L. Landen, L.J. Suter, P.J. Wegner \\ Lawrence Livermore National Laboratory \\ Livermore, CA 94551 \\ Email: lind11@1lnl.gov
}

The National Ignition Facility (NIF) ${ }^{\mathrm{i}, i \mathrm{i}}$ at Lawrence Livermore National Laboratory is a 192 beam, 1.8 MJ $0.35 \mu \mathrm{m}$ laser designed to drive inertial confinement fusion (ICF) capsules to ignition ${ }^{\text {iii }}$. NIF was formally dedicated in May 2009. The National Ignition Campaign, a collaborative research undertaking by LLNL, LLE, LANL, GA, and SNL, has a goal of achieving a robust burning plasma by the end of 2012. In the indirect-drive approach $^{\text {iv }}$, the laser energy is converted to thermal $\mathrm{x}$-rays inside a high $\mathrm{Z}$ cavity (hohlraum). The $\mathrm{x}$ rays then ablate the outer layers of a DT-filled capsule placed at the center of the hohlraum, causing the capsule to implode, compress and heat the DT and ignite.

Computer models of the implosion using the codes LASNEX ${ }^{\mathrm{V}}$ and HYDRA ${ }^{\mathrm{vi}}$, developed over the course of the US ICF Program, are extensively utilized to specify the point design target and the experiments required for the optimization of the implosion. Fig 1a shows a schematic of the point design hohlraum, Fig $1 \mathrm{~b}$ show the capsule design for the first ignition campaign and Fig 1c shows the laser pulse.

An extensive discussion of the point design and the methodology developed to establish specifications on the target, the laser, and the experimental campaign can be found in Ref. vii. Fabrication of the target is discussed in Ref. viii and laser performance is discussed in Ref. ix. The hohlraum is a $1 \mathrm{~cm}$-long, $5.44 \mathrm{~mm}$ diameter cylindrical hohlraum, designed with Au walls for current experiments, and filled with $0.9 \mathrm{mg} / \mathrm{cc}$ of He tamping gas. The hohlraum has two Laser Entrance Holes (LEH) of $\approx 55-60 \%$ of the hohlraum diameter. Details of the LEH and other features of the target will be finalized to optimize performance based on the results of ongoing experiments. To achieve x-ray irradiation symmetry, 24 sets of beams arranged in quads of 4 beams each enter from each end of the hohlraum in sets of $4,4,8$ and 8 at $23.5^{\circ}, 30^{\circ}, 44.5^{\circ}$ and $50^{\circ}$ from the hohlraum symmetry axis. The hohlraum is driven by a $1.3 \mathrm{MJ}, 20$ ns-long shaped pulse designed to implode the cryogenic fuel layer to a density in excess of $1000 \mathrm{~g} / \mathrm{cm}^{2}$. The current design ${ }^{\mathrm{x}}$ for the cryogenic capsule at hohlraum center is a graded Ge-doped ${ }^{\mathrm{xi}, \mathrm{xii}} \mathrm{CH}$ ablator of $918 \mu \mathrm{m}$ inside radius and $190 \mu \mathrm{m}$ shell thickness enclosing a $68 \mu \mathrm{m}$-thick layer of solid DT fuel initially held near the triple point ${ }^{\text {xiii }}$.

Laser requirements for ignition experiments on the NIF are set by two principal physics constraints. First, laser plasma interaction (LPI) effects limit the power and energy that can be delivered to a target while maintaining precise control of the temporal and spatial 
distribution of the deposition of that energy. This limit on the power and energy puts a limit on the pressure that can be generated during the implosion of a shell containing the fusion fuel. Second, at a given maximum pressure, there is a maximum velocity to which the fuel can be accelerated and this maximum velocity establishes the minimum fuel mass and driver energy required for ignition. Based on over two decades of experiments on the Nova and Omega lasers, NIF was designed and built to achieve ignition under these constraints.

Figure 1. a) Schematic of the $300 \mathrm{eV} \mathrm{CH}$ indirect-drive ignition target. b) Capsule cross-section. c) Total laser power (solid) and radiation temperature $\mathrm{Tr}$ at capsule (dashed) versus time.
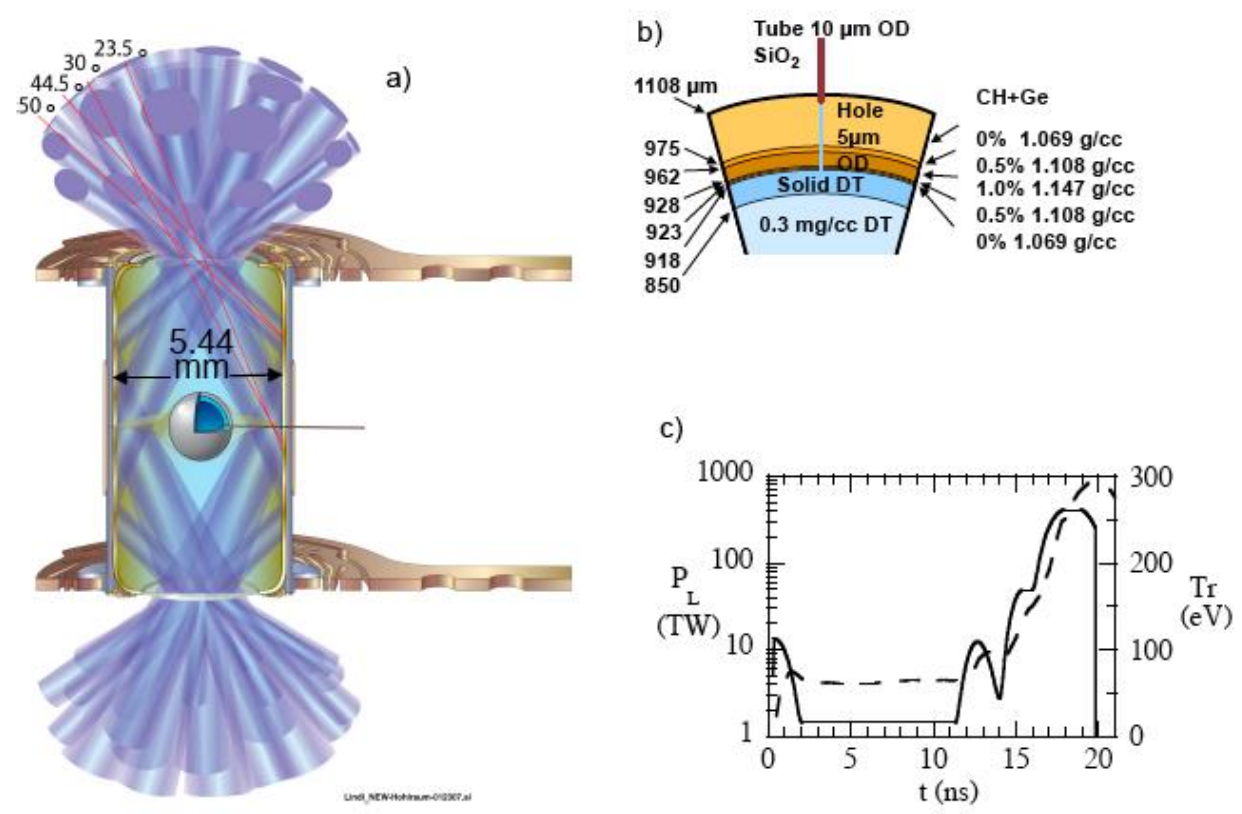

The fundamental input variables of an ICF implosion are the implosion velocity (V), fuel entropy (S) or adiabat $(\alpha)$, the shape of the central hot spot $\left(\mathrm{S}_{\mathrm{hs}}\right)$, and the mix $(\mathrm{M})$ of capsule and ablator on the outer surface of the dense fuel. Based on a comparison of the computer models with past experimental results, we have identified 14 laser and 3 target parameters shown in Fig. 2 which must be set precisely in experiments in order to optimize these key quantities in the imploded fuel assembly as required for ignition.

Based on these input variables, we have developed an input Ignition Threshold Factor (ITF) which describes the requirements for ignition. ITF is equivalent to a generalized Lawson Criterion for $\mathrm{ICF}^{\mathrm{xi}, \mathrm{xv}}$ and is given by the formula ${ }^{\mathrm{vii}}$ : 


$$
\mathrm{ITF}=I_{o}\left(\frac{M_{D T}}{M_{0}}\right)\left(\frac{v}{v_{0}}\right)^{8}\left(\frac{\alpha}{\alpha_{0}}\right)^{-4}\left(1-1.2 \frac{\Delta R_{\text {hot spot }}^{K-w t d}}{R_{\text {hot spot }}}\right)^{4}\left(\frac{M_{\text {clean }}}{M_{D T}}\right)^{0.5}\left(1-P_{H S}\right)
$$

ITF is a dimensionless quantity that is normalized to be unity when the expected thermonuclear yield equals the input laser energy. ITF is a measure of margin, and we define margin as ITF-1. $I_{0}$ is the ITF of the baseline optimized 1D implosion. It is about 4 for the point design shown in Fig. 1. Quantities with subscript zero are nominal values for the point design. If the implosion had nominal values of $v$ and $\alpha$, and were $1 \mathrm{D}$ - that is, $\Delta R_{\text {hotspot }}^{K-\text { wtd }}$ is zero and $M_{\text {clean }}=M_{D T}$ - then it would have $I_{0}$ times more fuel mass $\mathrm{M}_{\mathrm{DT}}$ than required for ignition. One can use up that factor of about 4 by reducing any of the terms until ITF is unity, at which point the expected gain is unity. In this equation, $\Delta R_{h o t s p o t}^{K-w t d}$ is the RMS deviation of the central hot spot from spherical. Non spherical hot spots produce less yield and reduce the margin of a 1D implosion.

Figure 2: To compensate for physics uncertainties, the experimental campaign will set 14 laser and 3 target parameters to optimize $V$, adiabat $\alpha$, ablator/fuel, mix, and hot spot shape

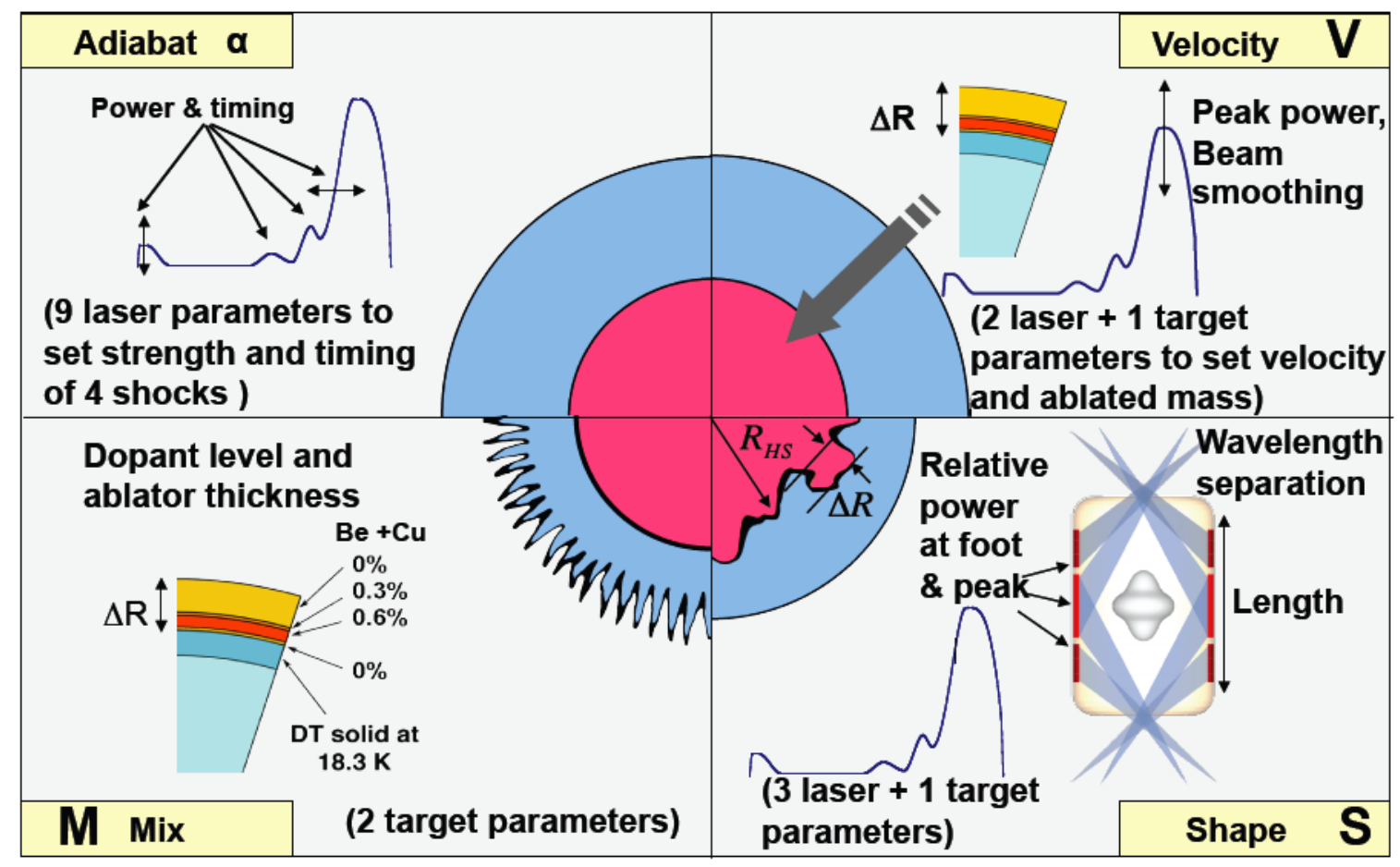

Similarly, $\mathrm{M}_{\text {clean }} / \mathrm{M}_{\mathrm{DT}}$ is the fraction of the fuel which contains less than $5 \%$ by mass of any ablator material which might have mixed into the main fuel layer during the implosion. Mix of ablator into the fuel reduces compressibility and dilutes the fuel. $\mathrm{P}_{\mathrm{hs}}$ is a measure of the purity of the hot spot and accounts for mix which penetrates all the way through the main fuel layer into the central gas region. This deep mix can cool the hot spot and reduce its yield. ITF is discussed in great detail in Ref. vii. 
Because of variability from shot to shot in the target and laser, and because of uncertainty in setting the key implosion parameters, there will be a range of ITF that will be achieved on any give shot. We have explored the expected distribution of ITF and the resulting target performance in an ensemble of $2 \mathrm{D}$ calculations which vary the laser, target, and experimental inputs within the ranges set by the point design specifications. The result of this ensemble of calculations is shown in Fig. 3a for expected variations of the Rev5-CH point design described in Ref. vii. For the point design shown in Fig. 1, we expect about $2 / 3$ of the shots to have a yield above $1 \mathrm{MJ}$ and a median yield of about $8 \mathrm{MJ}$. If we meet all of the specifications during the ignition campaign. These estimates will evolve as we obtain data in the experimental campaign and we can compare measured performance and variability with our current expectations. Shown in Fig $3 \mathrm{~b}$ is an equivalent formulation of the ignition factor, ITFX, based on the observable outputs of the implosion. This will be discussed below.

\section{Figure 3: a)Yield versus the Ignition Threshold factor (ITF) based on the inputs to an implosion, b) Yield versus an equivalent metric ITFX, based on observables of low yield THD implosions.}
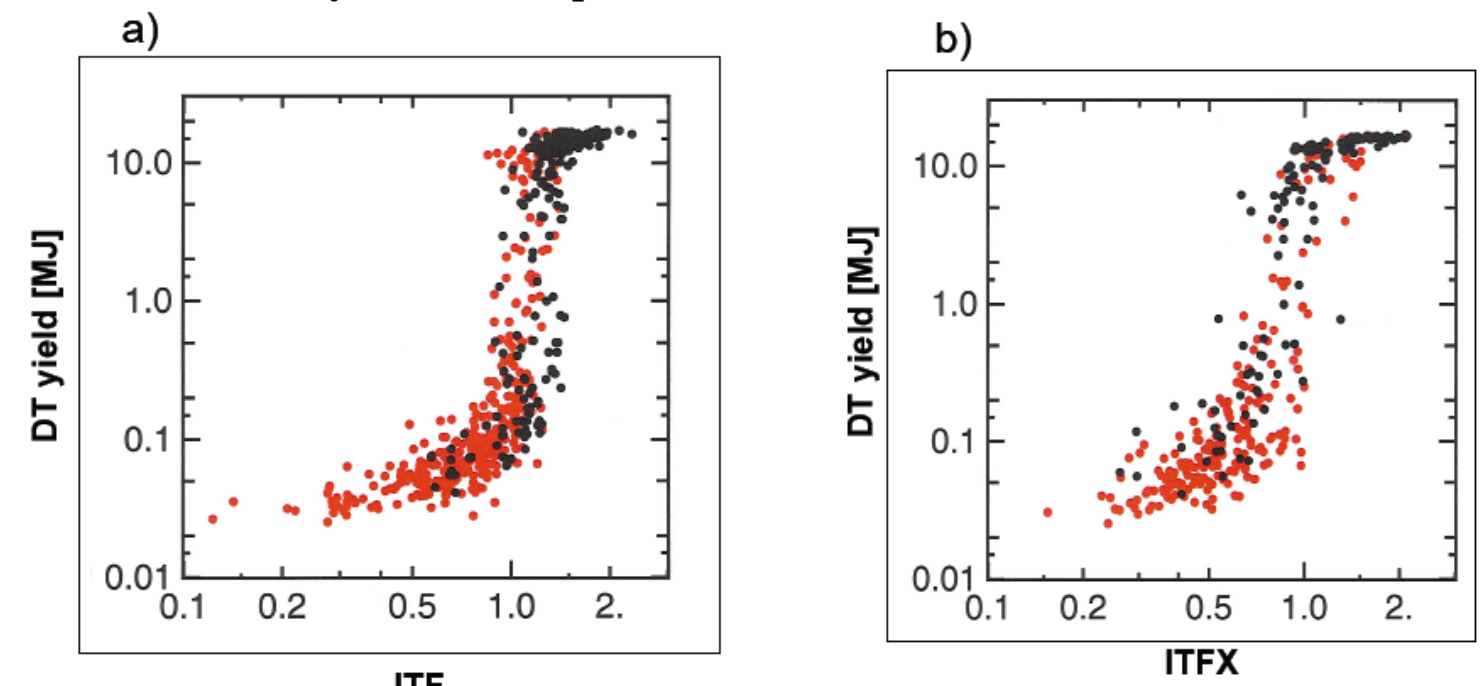

The point design target shown in Fig. 1 is designed to operate at a radiation temperature of $300 \mathrm{eV}$. Alternate ignition designes exist which span a range from $270 \mathrm{eV}$ to $300 \mathrm{eV}$ xvi,xvii,xviii,xix,xx,xxi . One of the most complex and challenging issues for ignition is the radiation temperature that can be achieved while meeting the ignition design requirements for drive, symmetry, and capsule preheat from hot electrons generated by Laser Plasma Interaction (LPI) processes, the most important of which in hohlraums is Stimulated Raman Scattering (SRS).

The hohlraum energetics campaign ${ }^{\text {xii }}$ with all 192 beams, began shortly after NIF dedication and ran until early December 2009. These experiments explored hohlraumoperating regimes in preparation for experiments with layered cryogenic targets, the first of which was carried out on September 29, 2010. The remainder of this paper 
summarizes the hohlraum energetics series and the first cyro-layered experiment including the capabilities which had to be developed to carry out these experiments.

Initial experiments in the hohlraum energetics campaign began at $500 \mathrm{~kJ}$ into a reduced scale hohlraum whose diameter and length were 0.86 those of the ignition hohlraum. The reduced energy was chosen so that we could gain operational experience with NIF before moving to higher energies. The series culminated with an experiment that irradiated an ignition scale hohlraum with $1 \mathrm{MJ}$, approximately thirty times the energy that any hohlraum has been irradiated previously. The results demonstrated the ability to produce a $285 \mathrm{eV}$ radiation environment in an ignition scale hohlraum while meeting ignition requirements for symmetry, backscatter and preheat. Complementary scaling experiments indicate that with $1.3 \mathrm{MJ}$, we will increase the capsule drive temperature to more than $300 \mathrm{eV}$, the point design temperature for the first the ignition target in Fig. 1.

Fig. 4: We demonstrated the ability to control implosion symmetry, using a "plasma-optical-switch" to transfer energy from outer to inner beams by increasing $\Delta \lambda=\lambda_{\text {inners }}-\lambda_{\text {outers }}$
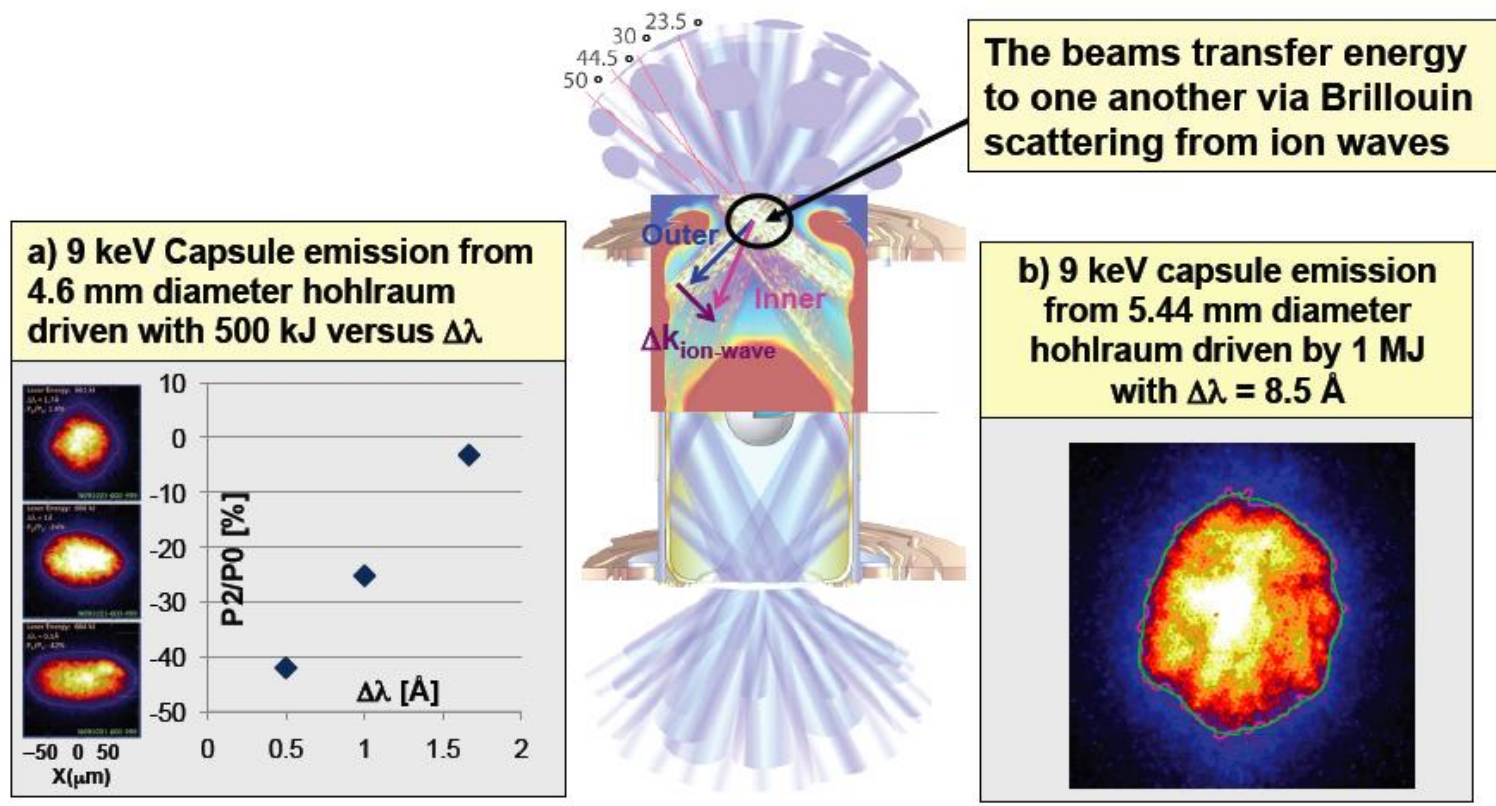

Radiation symmetry in NIF hohlraums is controlled by adjusting the relative powers between the inner beams at $23.5^{\circ}$ and $30^{\circ}$ and the outer beams at $44.5^{\circ}$ and $50^{\circ}$ or by changing the hohlraum length relative to its diameter. Controlling radiation symmetry has been a key aspect of ICF research on both the Nova and Omega lasers ${ }^{\text {iv }}$. The relative power between inner and outer beams can be varied directly by varying input power in the beams. This approach was demonstrated in a wide variety of experiments on Omega and is one of the techniques being used on NIF. However, on NIF, we also demonstrated the ability to control symmetry by transferring energy from outer to inner beams by changing their relative frequency by a few angstroms ${ }^{\text {xxii }}$. This novel cross-beam transfer 
is due to three-wave mixing ${ }^{\text {xxii }}$ where the beams cross in the flowing LEH plasmas. To utilize this approach to symmetry control, we employed different oscillators for the inner beams and the outer beams. Figure $4 \mathrm{a}$ shows the results of using this technique on the $4.6 \mathrm{~mm}$ diameter reduced scale hohlraum at an input energy of $\sim 500 \mathrm{~kJ}$. Shown are $9 \mathrm{keV}$ $\mathrm{x}$-ray images taken using the Gated X-ray Diagnositc $(\mathrm{GXD})^{\text {xxiv }}$ at peak $\mathrm{x}$-ray brightness

Figure 5: Radiation temperatures versus laser energy in NIF scale hohlraums follow a simple Marshak scaling law. The temperatures are also consistent with LASNEX calculations. Red points are for a $5.44 \mathbf{~ m m}$ diameter ignition scale hohlraum. Blue points are for a $4.6 \mathrm{~mm}$ diameter hohlraum

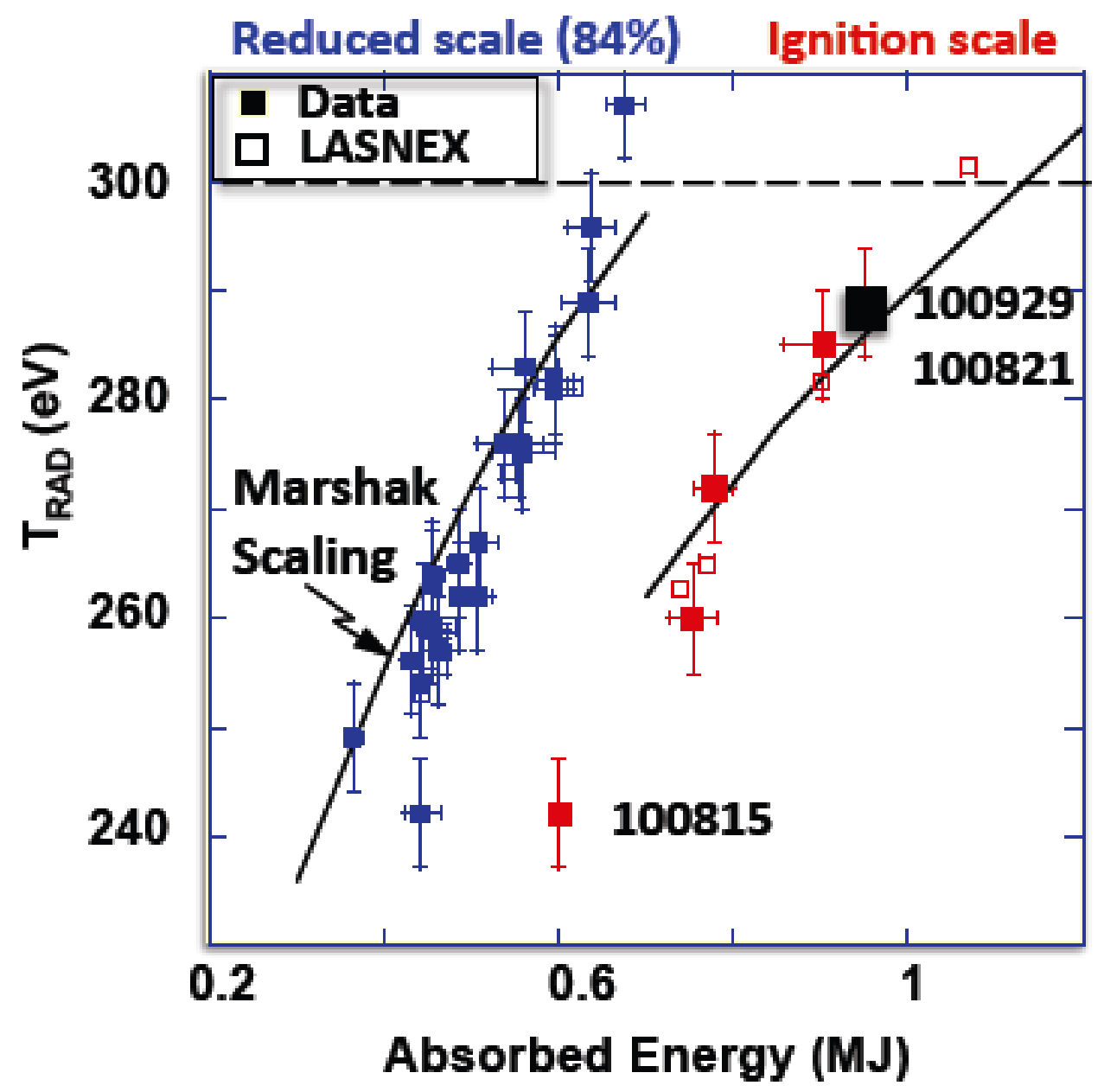

near the minimum radius of the implosion. This GXD takes a sequence of $70 \mathrm{ps}$ images, separated in time by about $30 \mathrm{ps}$ using an array of pinholes. This symmetry tuning technique was also demonstrated at $660 \mathrm{~kJ}$ in the $4.6 \mathrm{~mm}$ reduced scale hohlraum and them applied successfully at $1 \mathrm{MJ}$ into a full scale ignition hohlraum. The larger scale 
igntion hohlraums required about $8.5 \AA$ frequency shift to obtain the proper energy distribution in the hohlraum. Symmetry in ignition scale hohlraums, shown in Fig. $4 \mathrm{~b}$ for the Dec 09 megajoule shot, will be further optimized in the implosion optimization campaign in 2011.

Besides demonstrating the ability to control symmetry at the megajoule scale, the hohlraum energetics campaign demonstrated $>90 \%$ laser-plasma absorption using backscatter ${ }^{\mathrm{xxv}}$ and near backscatter ${ }^{\mathrm{xxvi}}$ optical diagnostics on a $30^{\circ}$ and $50^{\circ}$ beam quad, hot electron levels using a filter-fluorescer diagnostic ${ }^{\mathrm{xxvii}}$ which meet the ignition target specifications $^{\mathrm{vii}}$ and peak hohlraum thermal $\mathrm{x}$-ray production at expected levels using the multi-channel soft $\mathrm{x}$-ray power diagnostic Dante ${ }^{\mathrm{xxv} \text { viii }}$. Figure 5 shows radiation

temperature versus laser energy for the ignition scale $5.44 \mathrm{~mm}$ diameter hohlraum and the subscale $4.6 \mathrm{~mm}$ diameter hohlraum. These temperatures follow the expectations from a simple Marshak scaling ${ }^{\mathrm{iv}}$ and are also consistent with Lasnex calculations as shown. Based on analysis of these results, we expect to be able to further optimize hohlraum performance. Calculations indicate that we would be able to achieve symmetry with less cross beam transfer with a slightly shorter hohlraum, and that the cross beam transfer can by further optimized by using a third oscillator ${ }^{\text {xxix }}$. In addition, we intend to image hard $\mathrm{x}$ ray emission from the capsule to better quantify the fraction of preheat electron which reach the capsule.

The second stage of the ignition campaign involves utilizing this hohlraum to achieve the fuel conditions required for ignition. The key implosion parameters discussed above will be optimized in a set of specialized targets without cryogenic fuel layers as discussed extensively in Ref. xxx. The results of these experiments will be integrated into cyrolayered targets. These cryo-layered targets will initially be designed for low yield using a fuel layer composition consisting mainly of tritium and hydrogen with only a few percent deuterium, referred to as THD layers. These targets and their expected performance are discussed extensively in Ref.xxxi. By using these low yield targets, we will be able to maintain the full array of diagnostics needed to optimize the fuel assembly before shifting to a 50/50 DT layer to achieve ignition.

We find that the performance of these THD targets can be a good predictor of DT performance ${ }^{\mathrm{xxxii}}$. As shown in Figure $3 \mathrm{~b}$, the parameter, ITFX $=\left(\mathrm{Y} / \mathrm{Y}_{\mathrm{o}}\right) \mathrm{DSF}^{2.3}$ is found to be a good predictor of yield for a DT capsule with the same implosion parameters. $Y$ is the measured neutron primary yield (defined as the integral between $12-17 \mathrm{MeV}$ ), and $\mathrm{Y}_{\mathrm{o}}$ is a normalization constant chosen such that ITFX=1 when gain $=1$, where gain is defined as the ratio of the energy produced by the burning capsule to the laser energy into the hohlraum. $Y_{0}$ is a function of the deuterium fraction in the fuel. For $2 \% \mathrm{D}$, the neutron yield, $\mathrm{Y}$ is $\sim 10^{14}$, and $\mathrm{Y}_{\mathrm{o}}=$ $5 \times 10^{11}$. The DSF is the measured Down Scattered Fraction (defined as the number of neutrons between $10-12 \mathrm{MeV}$ expressed as a fraction of those between 12$17 \mathrm{MeV}$ ). The precise energy limits of DSF are not found to be significant. The motivation for the form of ITFX is derived both from the ITF formalism and the analysis of a generalized observable Lawson Criterion in $1 \mathrm{D}^{\text {Error! Bookmark not defined. }}$

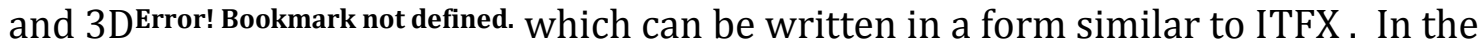


context of ITF, the mix and entropy terms in the ITF expression relate to $\rho$ R or equivalently DSF in ITFX, while velocity and shape in ITF relate to hot spot temperature and hot spot $\rho R$, which in turn relate to yield $Y$ in ITFX.

Preparation for the THD implosions has required installation of a variety of nuclear diagnostics, cryogenic layering target positioner, advanced optics, and facility modifications needed for tritium layered targets and for routine operation at laser energy greater than 1.3 MJ. Installation of this equipment has been a major focus of NIF during the first 9 months of 2010. Figure 6 shows the cryo-tarpos, the target positioner that was developed to allow the formation of cryogenic layers just outside the NIF target chamber prior to insertion of the target into the chamber.

Figure 6: Cryo-tarpos enables the formation of cryogenic layers just outside the NIF target chamber.

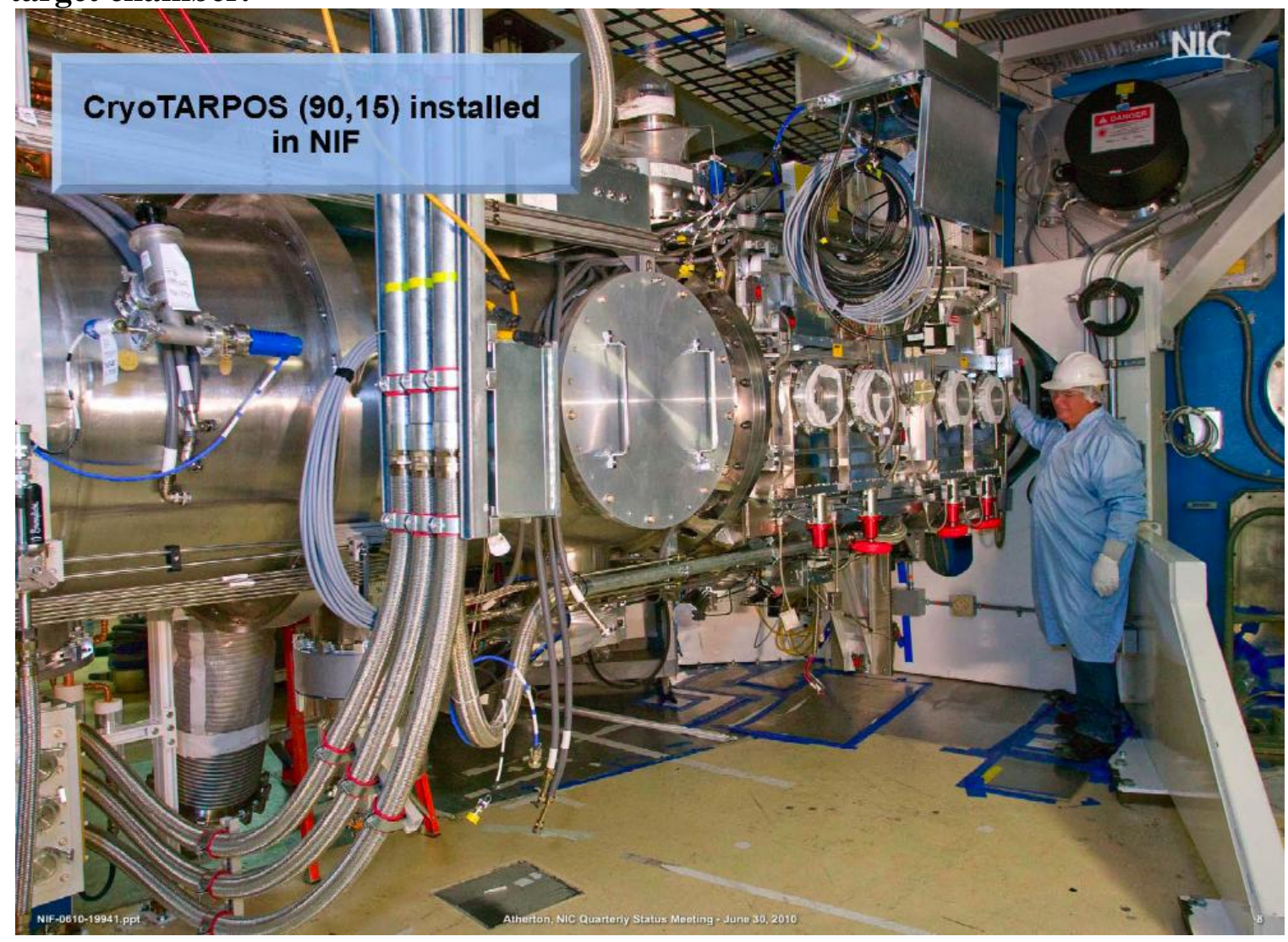

Figure 7 shows the tip of the cry-tarpos positioner arm including the partially open cryogenic shroud, which retracts a few seconds before shot time after the target is inserted into the chamber center. Also shown is the cryogenic target for the first cryogenic layered experiments attached to the positioner. Figure $8 \mathrm{~b}$ shows a NIF hohlraum designed for layering experiments. It includes a pair of viewing windows at the waist of the hohlraum. These viewing windows, and the LEH provide access for $\mathrm{x}$ ray phase contrast imaging of the layer, from three directions, as the layer forms. The fuel 
layer and the capsule ablator can be seen in such an image as shown in Figure 8a. The Hohlraum is fitted with two silicon arms at each end of the hohlraum to set the hohlraum operating temperature, and a pair of trim heating coils just inside of each arm for fine tuning of the low mode symmetry of the layer. By taking a sequence of $x$-ray images, we can watch the layer develop in time.

\section{Figure 7: Cryogenic shroud and target for the first THD shot on NIF}

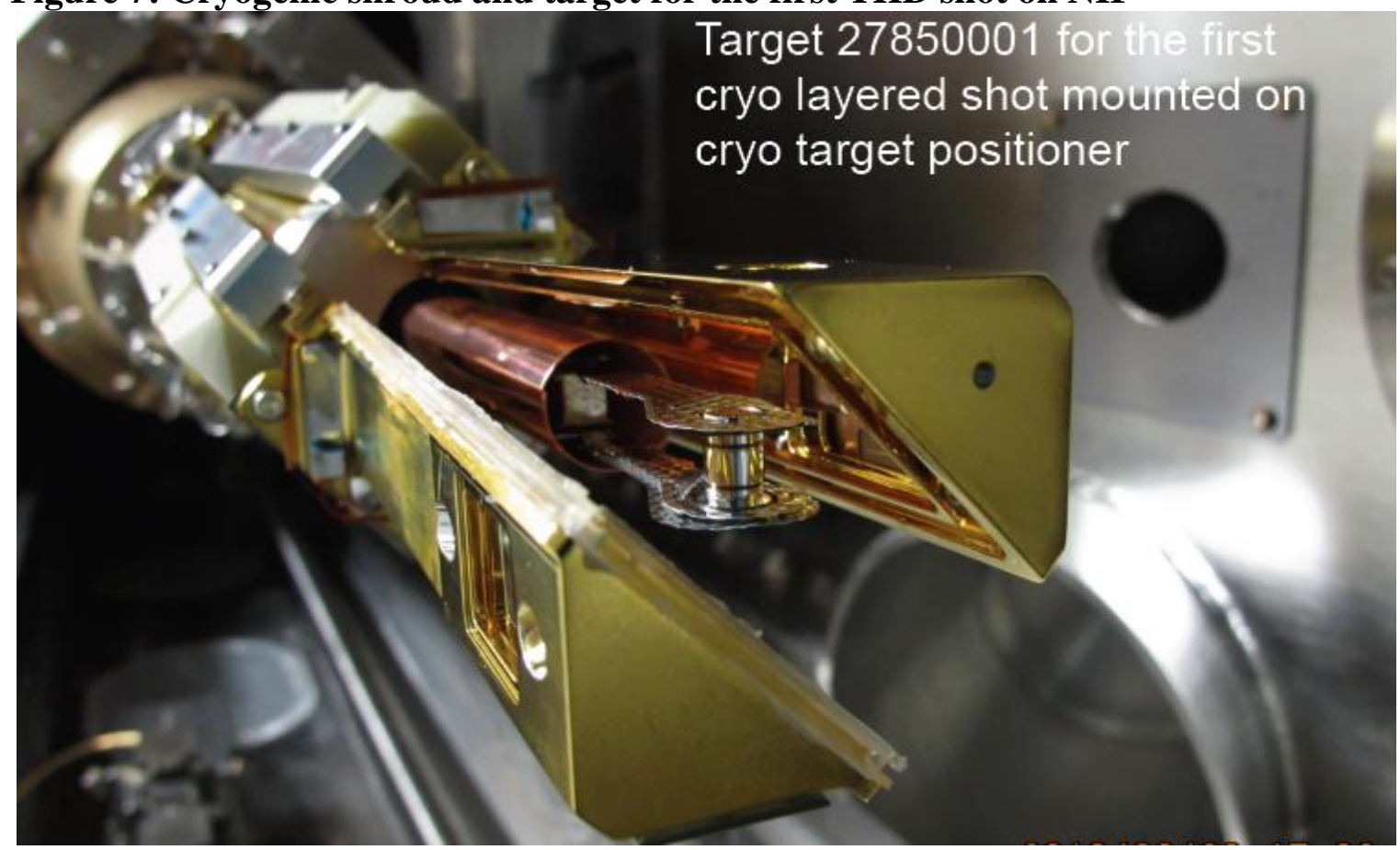

Figure 8: Cryo-fuel layers are imaged with $x$-rays from three directions through slots in the hohlraum at the hohlraum waist and through the laser entrance hole

a)

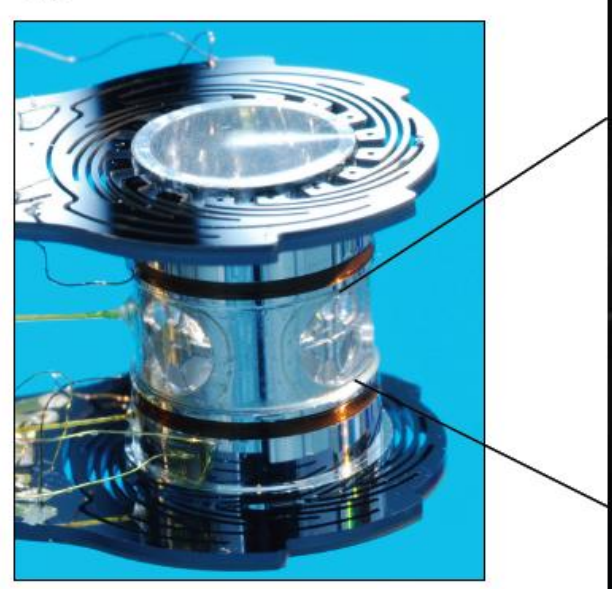

b)

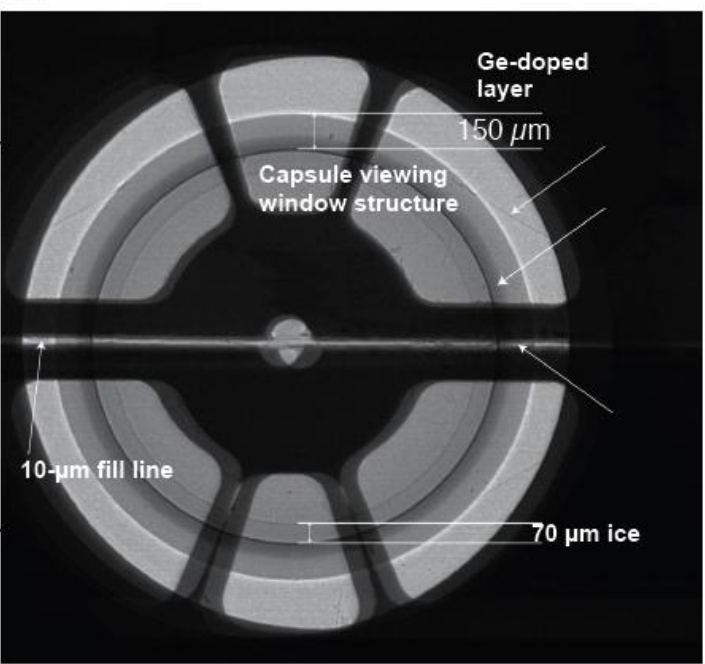


A wide range of new diagnostics was fielded on the first THD shot. This included several neutron time of flight detectors (NTOF) ${ }^{\mathrm{xxxiii}}$ at different distances from the chamber which will be used to measure the primary DT neutron yield and azimuthal variations, burn averaged ion temperature, and the fraction of neutrons scattered by the fuel, the DSF discussed above, which is proportional to $\rho \mathrm{R}$.. A number of detectors are required to cover the large range in neutron yields for THD and DT implosions. Several detectors located at $\sim 4 \mathrm{~m}$ from Target Chamber Center (TCC), are utilized for yield, ion temperature, and time of peak neutron emission (bang time) for the lower yield THD targets. An additional 2 detectors will be located at $\sim 20 \mathrm{~m}$ from TCC. These allow the neutron signal to dilate in time making it easier to measure the spectrum for the DSF. For DT yields, the close in detectors will no longer work and the $20 \mathrm{~m}$ detectors are relied on for all spectral information. The neutron spectrum will also be measured using a magnetic recoil spectrometer ${ }^{\mathrm{xxxiv}}$ (MRS), which provides an additional line of sight . This converts the neutron signal to a proton signal via collisions in a $\mathrm{CH}$ target foil. The proton spectrum is then measured by dispersing them spatially on to CR39 using a magnet. This diagnostic has been designed to work for the entire range of neutron yields from THD and DT targets.

Neutron activation detectors containing Zirconium [Zr90(n,2n)Zr89] will measure yield at several different azimuths to complement the nToF, and MRS detectors. The threshold energy for activation is $\sim 12 \mathrm{MeV}$ making this suitable for measuring the primary DT neutron signal. The yield is inferred by measuring absolutely the $\sim 909 \mathrm{keV}$ g-ray yield from the activated $\mathrm{Zr}$ nuclei. This is similar to copper activation technique also employed on NIF, but unlike $\mathrm{Cu}$ the $\mathrm{Zr}$ has a much longer half-life ( 3 days vs 10 mins) [30] making it functionally easier to implement .

Other new instruments included a Gamma Reaction HISTORY (GRH) or "burn history" diagnostic which is a 4-channel gas Cherenkov $\gamma$-ray detectorxxxv located $6 \mathrm{~m}$ from TCC. The $\gamma$ 's impact a converter foil producing electrons, which then produce Cerenkov radiation in the gas cells. The four cells will have different gas densities to produce gamma thresholds of 3, 5, 8 and $14 \mathrm{MeV}$. Data from these channels will be used to obtain the total yields and time history of three capsule gamma rays; 16.7 $\mathrm{MeV}$ gamma rays from a branch of the $\mathrm{D}+\mathrm{T}$ reaction, $19.8 \mathrm{MeV}$ from $\mathrm{T}+\mathrm{H}$ reaction, and $4.4 \mathrm{MeV}$ from neutrons interacting with the carbon in a plastic ablator.

A key feature of the THD implosions is that the neutron yield can be controlled via the $\% \mathrm{D}$ concentration in the fuel to optimize the diagnostics environment. It is expected that X-ray imaging will be feasible on NIF, without special relay optics to a shielded location, for neutron yields up to $\sim 10^{15}$ using a hardened gated $\mathrm{X}$-ray imager ${ }^{\mathrm{xxxvi}}$. This provides a large number of snapshots of the implosion for hot spot size and shape. Each image integrates over $\sim 35-70 \mathrm{ps}$, and a total interval $\sim 800 \mathrm{ps}$ can be covered, compared to the $100 \mathrm{ps}$ of the THD emission time. The spatial resolution is $\sim 5-10 \mu \mathrm{m}$ compared to the $\sim$ $25 \mu \mathrm{m}$ diameter of the X-ray image at peak brightness. Different filtering can be used to provide spectral discrimination on the same shot in order to extract temperature information $^{\mathrm{xxxvii}}$. A similar diagnostic, being built to operate in the $10^{17}$ range for implosions with higher $\% \mathrm{D}$ fills, must be located outside the target chamber with 
adequate shielding against the higher neutron environment. A faster camera is under development to provide $\sim 10$ ps resolution, which is on the same order as the burn width of igniting targets. NIF will soon have a neutron imager which will also provide time integrated spatial information of the hot spotxxxvii. The detector will be a stacked fiber scintillator located $28 \mathrm{~m}$ from the target, imaged by two cameras to produce one image of the primary neutrons, between $\sim 13$ and $20 \mathrm{MeV}$, and another gated from 10-12 MeV showing neutrons scattered within the capsule.

Bringing together all these new diagnostics, as well as the cryo-target positioner and all the additional infrastructure needed to carry out experiments with tritium in such a short period of time was a major undertaking. The main purpose of first THD cryo-layered experiment was to demonstrate the ability to integrate all the laser, target, and diagnostics capabilities needed for a successful experiment. The experiment carried out on September 29 fully demonstrated this capability. As shown by the black square in Fig. 5, the hohlraum achieved a radiation temperature of nearly $290 \mathrm{eV}$, consistent with expectations from the earlier non-layered hohlraum energetics series. However, we have done none of the optimization of symmetry, shock timing, velocity, or mix that will be required for THD capsules to reach the yield and DSF required for a DT capsule to ignite. Figure 9 shows a pair of $9 \mathrm{keV}$ GXD x-ray images taken near peak emission for the THD shot.

\section{Figure 9: A pair of GXD images from the THD shot near peak emission shows a jet of material passing through and cooling the hot spot.}
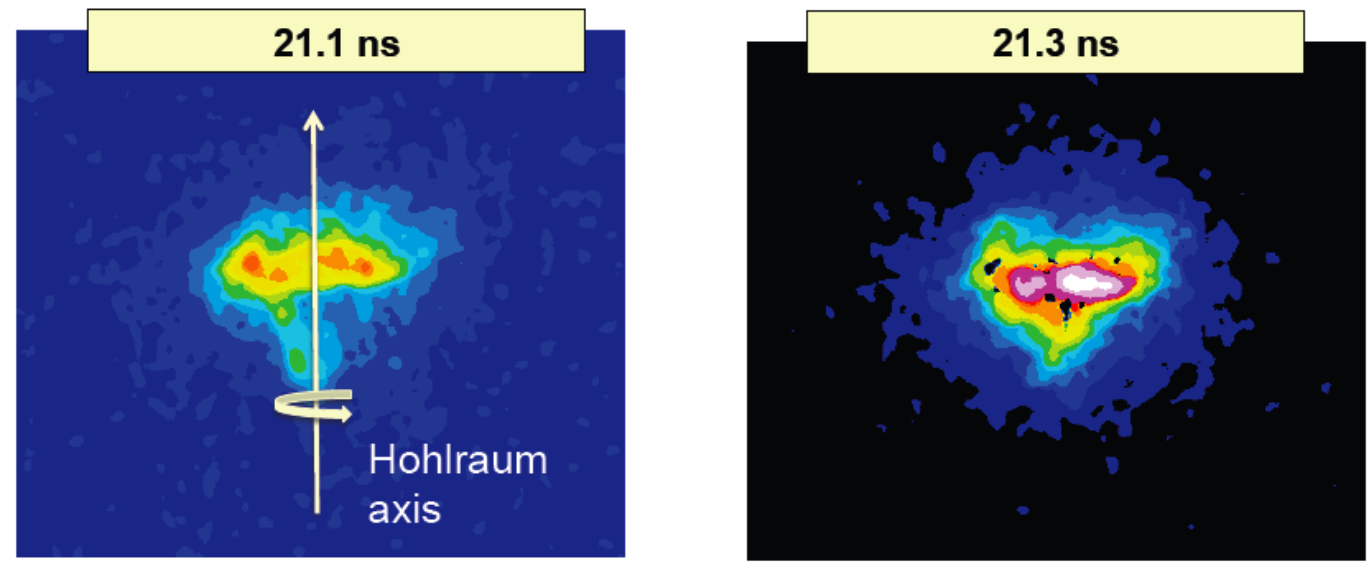

The implosion was "pancaked" along the hohlraum axis. This data indicates that in future THD shots we will need to improve the low mode symmetry as was done for the nonlayered implosions discussed above. Convergence ratios in THD implosions are a factor of two or more larger than for the non-layered implosions so the radiation flux and low mode capsule and cryo-layer uniformity must be proportionately better. Also there is a jet of material seen in the two images in Fig. 9. In the full sequence of images from the GXD, this jet passes through and appears to cool the hot spot. The jet is likely to have been generated by hydrodynamic instability growth of an isolated defect on the surface of the capsule. This data indicates that there is work to be done to further improve capsule 
surface features arising from dust and other assembly artifacts. Optimization of the THD fuel assembly using the surrogate tuning targets discussed above along with the THD implosions will be the focus of the coming year for the NIC.

The goal of the NIC campaign is a robust ignition target by the end of 2012. When successful, the ignition targets being explored by NIC in this first campaign, as well as higher performing targets at higher laser energy or with more efficient ablators, including Be and high density carbon (HDC), will lay the ground work for targets which meet the performance requirements for energy production for inertial fusion (IFE).

\section{Figure 10: Ignition experiments in 2011-2012 are expected to lay the groundwork for target performance which meets IFE requirement}

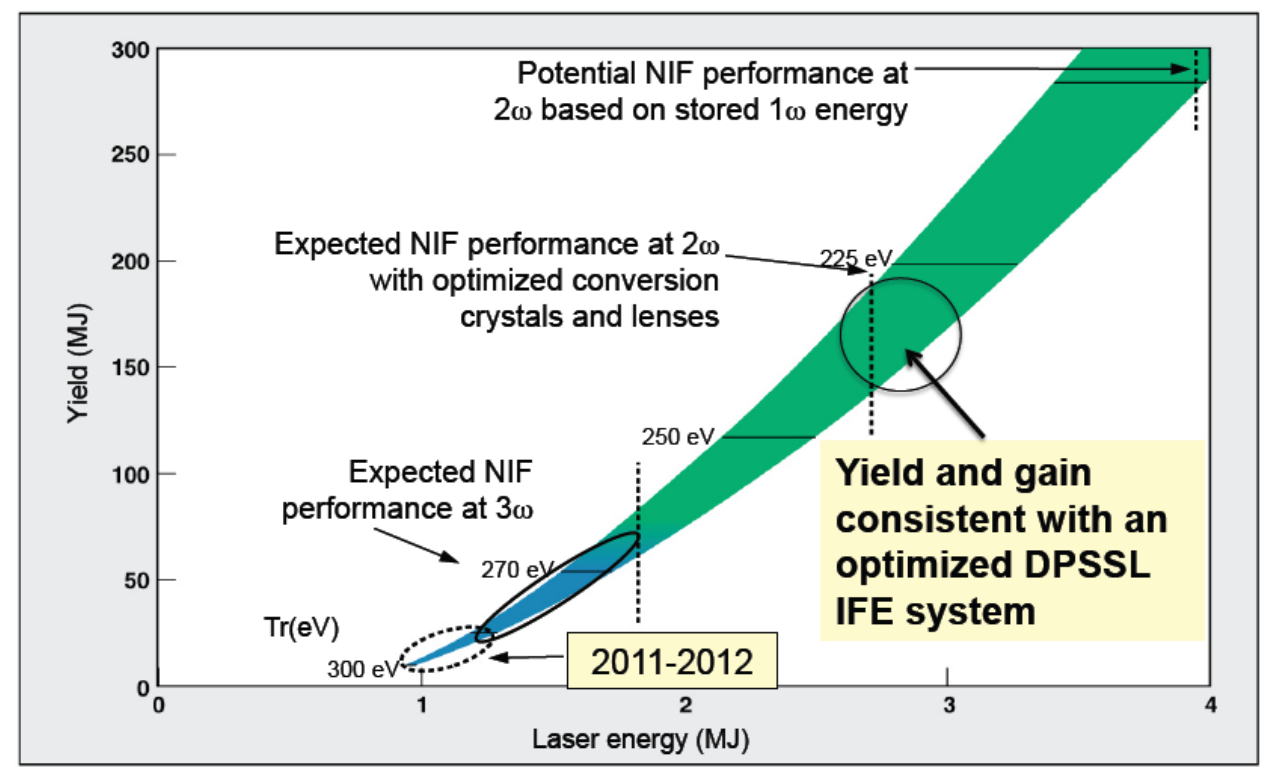

The expected performance of such targets is shown in Figure 10. This gain curve is based on direct extensions of NIC targets, keeping ITF constant as they move to higher laser energy and yield. At larger size, these targets have relatively more fuel and yield than the smaller NIC targets because they can ignite at lower velocity ${ }^{\text {iv }}$. NIF will be able to explore these targets up to energies of $1.8 \mathrm{MJ}$ of $3 \omega$ light at $0.35 \mu \mathrm{m}$. Because larger yield targets require lower implosion velocity, they can be imploded at lower hohlraum temperature and require correspondingly lower laser intensity in the hohlraum. NIF is capable of producing $3 \mathrm{MJ}$ or more of $2 \omega$ light at $0.53 \mu \mathrm{m}$ as indicated in Fig. 10 . Depending of the outcome of LPI experiments to be conducted at $2 \omega$ on NIF, it may be possible to achieve adequate hohlraum temperatures for these larger targets using this longer wavelength. If so, NIF would be able to explore the full range of targets needed for IFE.

In summary, initial hohlraum energetics experiments put us into the hohlraum temperature range for ignition experiments at $280-300 \mathrm{eV}$. The laser, diagnostic, target fabrication, cryo-layering target positioner, and other infrastructure capabilities needed for the ignition campaign are now in place. We have carried out the first THD cryolayered implosion demonstrating the ability to integrate all these capabilities. Based on 
our current understanding, following a successful tuning campaign, we will have a high probability of ignition with yields expected to be in the range of 5-10 MJ using $\mathrm{CH}$ capsules and hohlraums which require about $1.3 \mathrm{MJ}$ of laser energy. We expect these early ignition experiments to lay the ground work for target performance which meets IFE requirement.

This work performed under the auspices of the U.S. Department of Energy by Lawrence Livermore National Laboratory under Contract DE-AC52-07NA27344.

\footnotetext{
${ }^{\mathrm{i}}$ G.H. Miller, E.I. Moses and C.R. Wuest, Nucl. Fusion 44, 228 (2004).

${ }^{i i}$ E. I. Moses, R. N. Boyd, B. A. Remington, C. J. Keane, and R. Al-Ayat, Phys. Plasmas 16, 041006 (2009).

iii E.I. Moses, J. Phys.: Conf. Ser. 112, 012003 (2008); J.D. Kilkenny, T.P. Bernat, B.A. Hammel, R.L. Kauffman, O.L. Landen, J.D. Lindl, B.J. Macgowan, J.A. Paisner and H.T. Powell, Laser and Part. Beams 17, 159 (1999); Joseph D. Kilkenny, E. Michael Campbell, John D. Lindl, Grant B. Logan, Wayne R. Meier, L. John Perkins, Jeffrey A. Paisner, Michael H. Key, Howard T. Powell, Robert L. McCrory, and Wolf Seka, Phil. Trans. R. Soc. of Lond. A 357, 533 (1999).

iv J.D. Lindl, Phys Plasmas 2, 3933 (1995); J. D. Lindl, P. Amendt, R. L. Berger, S. G. Glendinning, S. H. Glenzer, S.W. Haan, R. L. Kauffman, O. L. Landen, and L. J. Suter, Phys. Plasmas 11, 339 (2004).

v G. B. Zimmerman and W. L. Kruer, Comments Plasma Phys. Controlled Fusion 2, 51 (1975).

${ }^{v i}$ M. M. Marinak, R. E. Tipton, O. L. Landen et al., Phys. Plasmas 3, 2070 (1996).

${ }^{v i i}$ S. W. Haan, J. D. Lindl, D. A. Callahan, D. S. Clark, J. D. Salmonson, B. A. Hammel, L. J. Atherton, R. C. Cook, M. J. Edwards, S. Glenzer, A. V. Hamza, S. P. Hatchett, D. E. Hinkel, D. D. Ho, O. S. Jones, O. L. Landen, B. J. MacGowan, M. M. Marinak, J. L. Milovich, E. I. Moses, D. H. Munro, S. M. Pollaine, J. E. Ralph, H. F. Robey, B. K. Spears, P. T. Springer, L. J. Suter, C. A. Thomas, R. P. Town, S. V. Weber, D. C Wilson, G. Kyrala, M. C. Herrmann, R. E. Olson, K. Peterson, R. Vesey, D. D. Meyerhofer, A. Nikroo, H. L. Wilkens, H. Huang, and K. A. Moreno, "Point design targets, specifications, and requirements for the 2010 ignition campaign on the National Ignition Facility", submitted to Phys. Plasmas viii L. J. Atherton, J. Phys.: Conf. Ser. 112, 032063 (2008).

${ }^{\text {ix }}$ C. A. Haynam, P. J. Wegner, J. M. Auerbach, M. W. Bowers, S. N. Dixit, G. V. Erbert, G. M. Heestand, M. A. Henesian, M. R. Hermann, K. S. Jancaitis, K. R. Manes, C. D. Marshall, N. C. Mehta, J. Menapace, E. Moses, J. R. Murray, M. C. Nostrand, C. D. Orth, R. Patterson, R. A. Sacks, M. J. Shaw, M. Spaeth, S. B. Sutton, W. H. Williams, C. C. Widmayer, R. K. White, S. T. Yang, and B. M. Van Wonterghem, Appl. Optics 46, 3276 (2007).

${ }^{x}$ S. W. Haan, J. D. Lindl, D. A. Callahan, D. S. Clark, J. D. Salmonson, B. A. Hammel, L. J. Atherton, R. C. Cook, M. J. Edwards, S. Glenzer, A. V. Hamza, S. P. Hatchett, D. E. Hinkel, D. D. Ho, O. S. Jones, O. L. Landen, B. J. MacGowan, M. M. Marinak, J. L. Milovich, E. I. Moses, D. H. Munro, S. M. Pollaine, J. E. Ralph, H. F. Robey, B. K. Spears, P. T. Springer, L. J. Suter, C. A. Thomas, R. P. Town, S. V. Weber, D. C Wilson, G. Kyrala, M. C. Herrmann, R. E. Olson, K. Peterson, R. Vesey, D. D. Meyerhofer, A. Nikroo, H. L. Wilkens, H. Huang, and K. A. Moreno, this Phys. Plasmas proceedings.

${ }^{x i}$ Daniel S. Clark, Steven W. Haan, Bruce A. Hammel, Jay D. Salmonson, Debra A. Callahan, and Richard P. J. Town, Phys. Plasmas 17, 052703 (2010).

xii S. W. Haan, M. C. Herrmann, T. R. Dittrich, A. J. Fetterman, M. M. Marinak, D. H. Munro, S. M. Pollaine, J. D. Salmonson, G. L. Strobel, and L. J. Suter, Phys. Plasmas 12, 056316 (2005).

xiii T. C. Sangster, R. Betti, R. S. Craxton, J. A. Delettrez, D. H. Edgell, L. M. Elasky, V. Yu. Glebov, V. N. Goncharov, D. R. Harding, D. Jacobs-Perkins, R. Janezic, R. L. Keck, J. P. Knauer, S. J. Loucks, L. D. Lund, F. J. Marshall, R. L. McCrory, P. W. McKenty, D. D. Meyerhofer, P. B. Radha, S. P. Regan, W. Seka, W. T. Shmayda, S. Skupsky, V. A. Smalyuk, J. M. Soures, C. Stoeckl, B. Yaakobi, J. A. Frenje, C. K. Li, R. D. Petrasso, F. H. Séguin, J. D. Moody, J. A. Atherton, B. D. MacGowan, J. D. Kilkenny, T. P. Bernat, and D. S. Montgomery Phys. Plasmas 14, 058101 (2007).

xiv C.D. Zhou and R. Betti, Phys. Plasmas 15, 102707 (2008)

xv P. Chang, R. Betti, B. K. Spears, K. S. Anderson, J. Edwards, M. Fatenejad, J. D. Lindl, R. L. McCrory, R. Nora, and D. Shvarts, Phys. Rev. Lett. 104, 135002(2010).
} 


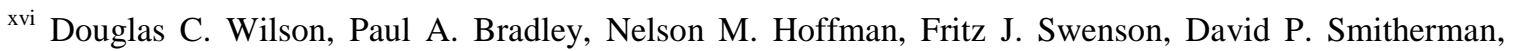
Robert E. Chrien, Robert W. Margevicius, D. J. Thoma, Larry R. Foreman, James K. Hoffer, S. Robert Goldman, Stephen E. Caldwell, Thomas R. Dittrich, Steven W. Haan, Michael M. Marinak, Stephen M. Pollaine, and Jorge J. Sanchez, Phys. Plasmas 5, 1953 (1998).

${ }^{\text {xvii }}$ T. R. Dittrich, S. W. Haan, M. M. Marinak, S. M. Pollaine, D. E. Hinkel, D. H. Munro, C. P. Verdon, G. L. Strobel, R. McEachern, R. C. Cook, C. C. Roberts, D. C. Wilson, P. A. Bradley, L. R. Foreman, and W. S. Varnum, Phys. Plasmas 6, 2164 (1999).

${ }^{\text {xviii }}$ D. A. Callahan, D. E. Hinkel, R. L. Berger, L. Divol, S. N. Dixit, M. J. Edwards, S. W. Haan, O. S. Jones, J. D. Lindl, N. B. Meezan, P. A. Michel, S. M. Pollaine, L. J. Suter, R. P. J. Town and P.A. Bradley, J. Phys.: Conf. Ser. 112, 022021 (2008).

${ }^{\text {xix }}$ A. Nikroo, K. C. Chen, M. L. Hoppe, H. Huang, J. R. Wall, H. Xu, M. W. McElfresh, C. S. Alford, R. C. Cook, J. C. Cooley, R. Fields, R. Hackenberg, R. P. Doerner and M. Baldwin, Physics of Plasmas 13, 056302 (2006).

${ }^{x x}$ K. C. Chen, R. C. Cook, H. Huang, S. A. Letts, and A. Nikroo, Fusion Sci. and Technol. 49, 750 (2006).

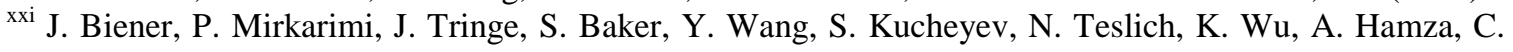
Wild, E. Woerner, P. Koidl, K. Bruelne, and H. Fecht, Fusion Sci. and Technol. 49, 737 (2006).

${ }^{x x i i}$ S. H. Glenzer, B. J. MacGowan, P. Michel, N. B. Meezan, L. J. Suter, S. N. Dixit, J. L. Kline, G. A. Kyrala, D. A. Callahan, E. L. Dewald, L. Divol, E. Dzenitis, M. J. Edwards, A. V. Hamza, C. A. Haynam, D. E. Hinkel, D. H. Kalantar, J. D. Kilkenny, O. L. Landen, J. D. Lindl, S. LePape, J. D. Moody, A. Nikroo, T. Parham, M. B. Schneider, R. P. J. Town, P. Wegner, K. Widmann, P. Whitman, B. K. F. Young, B. Van Wonterghem, J. E. Atherton, E. I. Moses, Science 327 (2010) 1228; N. B. Meezan, L. J. Atherton, D. A. Callahan, E. L. Dewald, S. Dixit, E. G. Dzenitis, M. J. Edwards, C. A. Haynam, D. E. Hinkel, O. S. Jones, O. Landen, R.A. London, P. A. Michel, J. D. Moody, J. L. Milovich, M B. Schneider, C. A. Thomas, R. P. J. Town, A. L. Warrick, S. V. Weber, K. Widmann, S. H. Glenzer, L. J. Suter, B. J. MacGowan, J. L. Kline, G. A. Kyrala, and A. Nikroo, Phys. Plasmas 18, (2010) 056304; S. H. Glenzer, B. J. MacGowan, N. B. Meezan, P. Adams, J. Alfonso, E. Alger, Z. Alherz, L. Alvarez, S. Alvarez, P. Amick, "Demonstration of ignition radiation temperatures in indirect-drive inertial confinement fusion hohlraums", submitted to Phys. Rev. Lett.

${ }^{x x i i i}$ P. Michel, L. Divol, E. A. Williams, S. Weber, C. A. Thomas, D. A. Callahan, S. W. Haan, J. D.

Salmonson, S. Dixit, D. E. Hinkel, M. J. Edwards, B. J. MacGowan, J. D. Lindl, S. H. Glenzer, and L. J. Suter, Phys. Rev. Lett. 102, 025004 (2009); P. Michel, L. Divol, E. A. Williams, C. A. Thomas, D. A. Callahan, S. Weber, S. W. Haan, J. D. Salmonson, N. B. Meezan, O. L. Landen, S. Dixit, D. E. Hinkel, M. J. Edwards, B. J. MacGowan, J. D. Lindl, S. H. Glenzer, and L. J. Suter, Phys Plasmas 16, 042702 (2009). xxiv John A. Oertel, Robert Aragonez, Tom Archuleta, Cris Barnes, Larry Casper, Valerie Fatherley, Todd Heinrichs, Robert King, Doug Landers, Frank Lopez, Phillip Sanchez, George Sandoval, Lou Schrank, Peter Walsh, Perry Bell, Matt Brown, Robert Costa, Joe Holder, Sam Montelongo, and Neal Pederson, Rev. Sci. Instrum. 77, 10E308 (2006).

${ }^{\mathrm{xxv}}$ D. H. Froula, D. Bower, M. Chrisp, S. Grace, J. H. Kamperschroer, T. M. Kelleher, R. K. Kirkwood, B. MacGowan, T. McCarville, N. Sewall, F. Y. Shimamoto, S. J. Shiromizu, B. Young, and S. H. Glenzer, Rev. Sci. Instrum. 75, 4168 (2004).

${ }^{x x v i}$ A. J. Mackinnon, T. McCarville, K. Piston, C. Niemann, G. Jones, I. Reinbachs, R. Costa, J. Celeste, G. Holtmeier, R. Griffith, R. Kirkwood, B. MacGowan, S. H. Glenzer, and M. R. Latta, Rev. Sci. Instrum. 75, 4183 (2004).

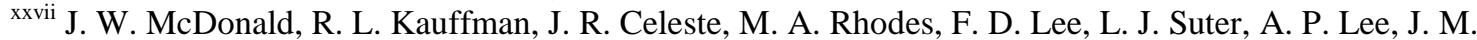
Foster, and G. Slark, Rev. Sci. Instrum. 75, 3753 (2004).

${ }^{x x v i i i}$ E. L. Dewald, K. M. Campbell, R. E. Turner, J. P. Holder, O. L. Landen, S. H. Glenzer, R. L. Kauffman, L. J. Suter, M. Landon, M. Rhodes, and D. Lee, Rev. Sci. Instrum. 75, 3759 (2004).

${ }^{\text {xxix }}$ P. Michel, L. Divol, R.P.J. Towne, M.D. Rosen, D.A. Callahan, N.B. Meezan, M.B. Schneider, G.A. Kyrala, J.D. Moody, E.L. Dewald, K. Widmann, E. Bond, J.L. Kline, C.A. Thomas, S. Dixit, E.A.

Williams, D.E. Hinkel, R.L. Berger, O.L. Landen, M.J. Edwards, B.J. Macgowan, J.D. Lindl, C. Haynam, L.J. Suter, S.H. Glenzer, and E. Moses, "A three wavelength scheme to optimize hohlraum coupling on the National Ignition Facility", submitted to Phys. Rev. Letters

${ }^{\mathbf{x x x}}$ O. L. Landen, J. Edwards, S.W. Haan, H. F. Robey, J. Milovich, B. K. Spears, S. V. Weber, D.S. Clark, J. D. Lindl, B. J. MacGowan, E. I. Moses, J. Atherton, P. A. Amendt, T. R. Boehly, D. K. Bradley, D. G. Braun, D. A. Callahan, P. M. Celliers, G. W. Collins, E. L. Dewald, L. Divol, J. A. Frenje, S. H. Glenzer, 
A. Hamza, B. A. Hammel, D. G. Hicks, N. Hoffman, N. Izumi, O. S. Jones, J. D. Kilkenny, R. K. Kirkwood, J. L. Kline, G. A. Kyrala, M. M. Marinak, N. Meezan, D. D. Meyerhofer, P. Michel, D. H. Munro, R. E. Olson, A. Nikroo, S. P. Regan, L. J. Suter, C. A. Thomas, and D. C. Wilson, "Capsule Implosion Optimization during the Indirect-Drive National Ignition Campaign", submitted to Phys. Plasmas

xxxi M. J. Edwards, L. J. Atherton, D. L. Bleuel, D.K. Bradley, D. A. Callahan, C. J. Cerjan, D Clark, G. W. Collins, J. E. Fair, R. J. Fortner, S. H. Glenzer, S. W. Haan, A. V. Hamza, S. P. Hatchett, B. Jacoby, O. S. Jones, J. A. Koch, B. J. Kozioziemski, O. L. Landen, RLerche, J. D. Lindl, B. J. MacGowan, A. J. MacKinnon, E. R. Mapoles, M. M. Marinak, M. Moran, E. I. Moses, D. H. Munro, D. H. Schneider, S. M. Sepke, D. A. Shaughnessy, B. K. Spears, P. T. Springer, R. Tommasini, R. Betti, T. R. Boehly, T.C. Sangster, V. Yu. Glebov, P. W. McKenty, S. P. Regan, D. H. Edgell, J.P. Knauer, C. Stoeckl, D. R. Harding, G. Grim, H. W. Herrman, G. Kyrala, M. Wilke, D. C. Wilson, J. Frenje, R. Petrasso, Kari Moreno, Haibo Huang, KC Chen, Emilio Giraldez, J. D. Kilkenny, Michael Mauldin, Nicholas Hein, Marty Hoppe, Abbas Nikroo, and R. Leeper, "The Experimental Plan for Cryogenic Layered Target Implosions on the National Ignition Facility - the Inertial Confinement Approach to Fusion", submitted to Phys. Plasmas

xxxii B.K. Spears et al, "Prediction of Ignition Implosion Performance from Low Deuterium Surrogates", to be published in J. Phys.: Conf. Ser.

xxxiii Z. A. Ali, V.Y. Glebov, M. Cruz, T. Duffy, C. Stoeckl, S. Roberts, T.C. Sangster, R. Tommasini, A. Throop, M. Moran, L. Dauffy, and C. Horsefield RSI 79, 10E527 (2008); V. Y. Glebov, D.D. Meyerhofer, T.C. Sangster, C. Stoeckl, S. Roberts, C.A. Barrera, J.R. Celeste, C.J. Cerjan, L.S. Fauffy, D.C. Eder, R.L. Griffith, S.W. Haan, B.A. Hammel, S.P. Hatchett, N. Izumi, J.R. Kimbrough, J.A. KocK, O.L. Landen, R.A. Lerche, B.J. MacGowan, M.J. Moran, E.W. Ng, T.W. Phillips, P.M. Song, R. Tommasini, B.K. Young, S.E. Caldwell, G.P. Grim S.C. Evans, J.M. Mack, T.J. Sedillo, M.D. Wilke, D. Casey, J.A. Frenje, C.K. Li, R.D. Petrasso, F. H. Sequin, J.L. Bourgade, L. Disdier, M. Houry, I. Lantuejoul, O. Landoas, G. A. Chandler, G.W. Cooper, R.J. Leeper, R.E. Olson, C.L. Ruiz, M.A. Sweeney, S.P. Padalino, C. Horsfield, B.A. Davis, RSI 77, 10E715 (2006); V.Y. Glebov, C. Stoeckl, T.C. Sangster, S. Roberts, R.A. Lerche, G.J. Schmid, IEEE TRANSACTIONS ON PLASMA SCIENCE 33, 70-76 (2005); V.Y. Glebov, C. Stoeckl, T.C. Sangster, S. Roberts, G.J. Schmid R.A. Lerche and M.J. Moran, RSI 75, 3559 (2004); G.J. Schmid, R.L. Griffith, N. Izumi, J.A. Koch, R.A. Lerche, M.J. Moran, T.W. Phillips, R.E. Turner, V. Y. Glebov, T.C. Sangster, and C. Stoeckl, RSI 74, 1828-1831 (2003).

xxxiv J. A. Frenje, D. T. Casey, C. K. Li, F. H. Seguin, R. D. Petrasso, V. Y. Glebov, P. B. Radha, T. C. Sangster, D. D. Meyerhofer, S. P. Hatchett, S. W. Haan, C. J. Cerjan, O. L. Landen, K. A. Fletcher, and R. J. Leeper, Probing high areal-density cryogenic deuterium-tritium implosions using downscattered neutron spectra measured by the magnetic recoil spectrometer (AIP, ADDRESS, 2010), No. 5, p. 056311.

${ }^{x x x v}$ H. W. Herrmann, C.S. Young, J.M. Mack, Y.H. Kim, A. McEvoy, S. Evans, T. Sedillo, S. Batha, M. Schmitt, D.C. Wilson, J.R. Langenbrunner, R. Malone, M.I. Kaufman, B.C. Cox, B. Frogger, E.K. Miller, Z.A. Ali, T. W. Tunnell, W. Stoeffl, C.J. Horsfield, and M. Rubery, Journal of Physics: Conference Series 244 (2010) 032047

${ }^{\text {xxvi }}$ N Izumi, G Stone, C Hagmann, C Sorce, D K Bradley, M Moran, O L Landen, P Springer, W Stoeffl, R Tommasini, H W Hermann1, G A Kyrala1, V Y Glebov, J Knauer, T C Sangster, and J A Koch , "Experimental evaluation of neutron induced noise on gated x-ray framing cameras", to be published in $J$. Phys.: Conf. Ser

xxxvii J.A Koch, S. W. Haan, R.C. Mancini, Journal of Quantitative Spectroscopy, 88, 433, (2004).

xxxviii E. Loomis, G. Grim, C. Wilde, D.C. Wilson, M. Wilke, J. Finch, G. Morgan, I. Tregillis, D. Clark, Journal of Physics: Conference Series 244 (2010) 032051 